\title{
HDAC is essential for epigenetic regulation of Thy-1 gene expression during LPS/TLR4-mediated proliferation of lung fibroblasts
}

\author{
Shunpeng Xing 1,3, Fang Nie1,3, Qiaoyi Xu', Yuxiao Deng ${ }^{1}$, Wen $\mathrm{Li}^{1}$, Zhongwei Yang ${ }^{2}$, Xianyuan Zhao ${ }^{1}$, Ping Zhu ${ }^{1}$, \\ Xiangrui Wang ${ }^{2}$, Yuan Gao ${ }^{1}$ and Zhengyu $\mathrm{He}^{1}$
}

Lipopolysaccharide (LPS)-induced proliferation of lung fibroblasts is closely correlated with loss of gene expression of thymocyte differentiation antigen-1 (Thy-1), accompanied with deacetylation of histones $\mathrm{H} 3$ and $\mathrm{H} 4$ at the Thy-1 gene promoter region; however, the mechanism remains enigmatic. We report here that LPS downregulates Thy-1 gene expression by activating histone deacetylases (HDACs) via Toll-like receptor 4 (TLR4) signaling. Treatment of primary cultured mouse lung fibroblasts with LPS resulted in significant upregulation of TLR4 and enhanced cell proliferation that was abolished by silencing TLR4 with lentivirus-delivered TLR4 shRNA. Interestingly, LPS increased the mRNA and protein levels of HDAC-4, -5 , and -7 , an effect that was abrogated by HDAC inhibitor trichostatin A (TSA) or TLR4-shRNA-lentivirus. Consistent with these findings, Ace-H3 and Ace-H4 were decreased by LPS that was prevented by TSA. Most importantly, chromosome immunoprecipitation (ChIP) analysis demonstrated that LPS decreased the association of Ace-H4 at the Thy-1 promoter region that was efficiently restored by pretreatment with TSA. Accordingly, LPS decreased the mRNA and protein levels of Thy- 1 that was inhibited by TSA. Furthermore, silencing the Thy- 1 gene by lentivirus-delivered Thy- 1 shRNA could promote lung fibroblast proliferation, even in the absence of LPS. Conversely, overexpressing Thy-1 gene could inhibit lung fibroblast proliferation and reduce LPS-induced lung fibroblast proliferation. Our data suggest that LPS upregulates and activates HDACs through TLR4, resulting in deacetylation of histones $\mathrm{H} 3$ and $\mathrm{H} 4$ at the Thy- 1 gene promoter that may contribute to Thy-1 gene silencing and lung fibroblast proliferation.

Laboratory Investigation (2015) 95, 1105-1116; doi:10.1038/labinvest.2015.97; published online 27 July 2015

Pulmonary fibrosis is characterized by aberrant proliferation and activation of lung fibroblasts. ${ }^{1,2}$ The phenotypic transition of lung fibroblasts during the process of pulmonary fibrosis can be stimulated by various pathological conditions, including lipopolysaccharide (LPS), a component of bacteria membranes and an important player during the development of pulmonary fibrosis., ${ }^{3,4}$ LPS-induced proliferation of lung fibroblast is associated with the silencing of thymocyte differentiation antigen-1 (Thy-1) and deacetylation of histones $\mathrm{H} 3$ and $\mathrm{H} 4$ at the Thy- 1 gene promoter; ${ }^{5,6}$ however, the mechanism by which LPS promotes the deacetylation of histones $\mathrm{H} 3$ and $\mathrm{H} 4$ leading to downregulation of Thy-1 gene expression is largely unknown.
Thy- 1 is a cell surface glycoprotein that is present in normal lung fibroblasts but absent from the fibroblastic foci of idiopathic pulmonary fibrosis (IPF). ${ }^{7}$ Heterogeneous surface expression of Thy- 1 in fibroblasts results in the specialization of fibroblast, including Thy-1 (+) and Thy-1 (-) subsets. Hagood et al ${ }^{5,8,9}$ reported that lack of Thy-1 expression on lung fibroblasts contributed to IPF. Recently, it was found that epigenetic mechanisms, such as promoter hypermethylation and histone modification, play an important role in Thy-1 gene silencing in lung fibroblasts. ${ }^{6,7}$ Our previous study has revealed that the epigenetic regulation of Thy- 1 gene expression by histone modification, including the deacetylation of histones $\mathrm{H} 3$ and $\mathrm{H} 4$, is involved in LPS-

${ }^{1}$ Department of Critical Care Medicine, Ren Ji Hospital, School of Medicine, Shanghai Jiao Tong University, Shanghai, China and ${ }^{2}$ Department of Anesthesiology, Ren Ji Hospital, School of Medicine, Shanghai Jiao Tong University, Shanghai, China

Correspondence: Dr Z He, MD, PhD or Dr Y Gao, MD, PhD, Department of Critical Care Medicine, Ren Ji Hospital, School of Medicine, Shanghai Jiao Tong University, 160 Pu Jian Road, Shanghai 200127, China.

E-mail: zhengyuheshsmu@163.com or gaoyuanshsmu@163.com

${ }^{3}$ These authors contributed equally to this work.

Received 28 December 2014; revised 5 June 2015; accepted 23 June 2015 
induced phenotypic transition and proliferation of lung fibroblast through its specific receptor Toll-like receptor 4 (TLR4). ${ }^{10}$ However, the mechanism of LPS-induced histone deacetylation in lung fibroblasts during the process of pulmonary fibrosis remains enigmatic.

The process of histone deacetylation is regulated by histone deacetylases (HDACs), a class of enzymes that remove acetyl from lysine residues within histones. HDACs are activated during LPS-induced acute lung injury (ALI). ${ }^{11}$ Moreover, activated HDACs were found to be associated with the silencing of Thy- 1 gene on lung fibroblasts from patients with IPF. ${ }^{6}$ Therefore, we speculate that HDACs may be activated by LPS and play a role in the process of LPS-induced histone deacetylation, Thy-1 silencing, and proliferation.

In this study, we have investigated the epigenetic effect of HDACs on LPS-induced histone deacetylation, Thy-1 silencing, and proliferation of lung fibroblasts by knocking down TLR4 expression with lentivirus-based RNA interference (RNAi) and pharmacologic inhibition of HDACs with HDAC-specific inhibitor trichostatin A (TSA). We also evaluate the functions of Thy-1 in LPS-induced lung fibroblast proliferation by down- or upregulating Thy-1 gene expression.

\section{MATERIALS AND METHODS \\ Cell Culture}

Mouse lung fibroblasts (MIC-CELL-0040) were obtained from Wuhan Pricells Biotechnology \& Medicine (Wuhan, China), and cultured in Dulbecco's modified Eagle's medium (DMEM) supplemented with $10 \%$ fetal calf serum, $2 \mathrm{mM}$ L-glutamine, $100 \mathrm{IU} / \mathrm{ml}$ penicillin $\mathrm{G}$, and $100 \mathrm{IU} / \mathrm{ml}$ streptomycin at $37{ }^{\circ} \mathrm{C}$ in a humidified $5 \% \mathrm{CO}_{2}$ incubator (Thermo Fisher, Waltham, MA, USA). The medium and supplements were obtained from Gibco BRL (Labotect, Gottingen, Germany). Medium was changed every 3 days. When cells reached $80 \%$ confluence, adherent cells were detached by $0.25 \%$ trypsin and seeded into 6-well plates at 1:5-10 dilutions, depending on the requirements of the particular experiment. The cell densities were allowed to grow to $\sim 20 \%$ confluence in each well and passages 5 through 7 were used in this study.

\section{Reagents and Antibodies}

A specific small interfering RNA (siRNA) lentivirus vector targeting TLR4 (TLR4-siRNA-lentivirus) was obtained from Shanghai GeneChem (Shanghai, China). The construction and verification of TLR4-siRNA-lentivirus has been described previously. ${ }^{12}$ HDAC inhibitor TSA and purified LPS (derived from O55:B5 E. coli) were obtained from Sigma (St Louis, MO, USA). Antibodies against TLR4, HDAC-4, histone H3, acetylated histone $\mathrm{H} 3$, histone $\mathrm{H} 4$, acetylated histone $\mathrm{H} 4$, and GAPDH were purchased from Cell Signaling Technology (Boston, MA, USA). Anti-HDAC-5, HDAC-7, and Thy-1 antibodies were obtained from Abcam (Cambridge, UK). Goat anti-mouse IgG and goat anti-rabbit IgG secondary antibodies were from Santa Cruz Biotechnologies (Santa Cruz, CA, USA).

Construction and Identification of Thy-1 RNAi Lentivirus Lentiviral vector targeting Thy-1 (Thy-1-siRNA-lentivirus) was constructed and verified by Shanghai GeneChem. A 19nucleotide (5'-ATAGAGACAAGCTGGTCAA-3') siRNA was designed against the mouse Thy-1 mRNA (GenBank accession number NM_009382). Scrambled siRNA, which was used as negative control in the experiment, is an irrelevant siRNA with random nucleotides (5'-TTCTCCGAACGT GTCACGT-3'). The siRNAs were synthesized and inserted between the AgeI and EcoRI restriction sites of the plasmid pGCSIL-GFP. Correct insertion of siRNAs was confirmed by restriction mapping and direct DNA sequencing. Recombinant lentiviruses were produced by co-transfecting 293T cells with the pGCSIL-GFP plasmid together with the two packaging plasmids pHelper 1.0 (encoding human immunodeficiency virus (HIV) gag, pol, and rev) and plasmid pHelper 2.0 (encoding for VSV-G envelop) using Lipofectamine 2000 (Invitrogen, Carlsbad, CA, USA) according to the manufacturer's instructions. Infectious lentivirus was harvested at $48 \mathrm{~h}$ after transfection, centrifuged to remove cell debris, and then filtered through a $0.45 \mu \mathrm{m}$ cellulose acetate filter, and finally centrifuged at $50000 \mathrm{~g}$ for $90 \mathrm{~min}$. The virus sediments (Thy1-siRNA-lentivirus) were collected. After the titers were determined, Thy-1-siRNA-lentivirus was used to infect mouse lung fibroblasts at a concentration of $1 \times 10^{8}$ transducing units (TUs) $/ \mathrm{ml}$ for $48 \mathrm{~h}$.

\section{Construction and Identification of Thy-1 Overexpression Lentivirus}

A Thy-1 overexpression lentivirus (Thy-1-OE-lentivirus) was constructed and verified by Shanghai GeneChem. Thy-1 gene was amplified from a cDNA library via PCR (forward: 5'-GA GGATCCCCGGGTACCGGTCGCCACCATGAACCCAGCCA TCAGCG- $3^{\prime}$ and reverse: $5^{\prime}$-TCACCATGGTGGCGACCGGC AGAGAAATGAAGTCCAGG-3'). The cDNA digested with AgeI was cloned into an AgeI-digested pGC-FU-3FLAG (GV208) lentivirus vector (GeneChem). The resulting vector carrying the Thy- 1 gene fragment was transformed into DH $5 \alpha$ competent cells. Positive clones containing the Thy- 1 coding sequence were selected by PCR. The resulting lentivirus vector together with pHelper1 and pHelper2 vectors were cotransfected into 293T cells for $24 \mathrm{~h}$ using Lipofectamine 2000 to generate Thy-1-OE-lentivirus. After the titers were determined, Thy-1-OE-lentivirus was used to infect mouse lung fibroblasts at a concentration of $5 \times 10^{4} \mathrm{TUs} / \mathrm{ml}$ for $48 \mathrm{~h}$.

\section{Experimental Groups and Treatment}

Purified mouse lung fibroblasts were seeded into 96-well plates and grown in DMEM containing 10\% calf serum in a humidified atmosphere containing $5 \% \mathrm{CO}_{2}$. When $\sim 60 \%$ confluence was reached, the medium was replaced with serum-free medium and the cultures were incubated for an 
additional $24 \mathrm{~h}$ at $37^{\circ} \mathrm{C}$ in $5 \% \mathrm{CO}_{2}$. Finally, the serum-free medium was replaced with DMEM containing $10 \%$ calf serum and the cells were divided into several groups: Blank Control (Con. B): cells received no treatments; Negative Control (Con. N): cells were infected with control-siRNAlentivirus containing scrambled nonfunctional RNAi sequences and/or dimethylsulfoxide (DMSO); LPS challenge (LPS): cells were challenged with LPS; TLR4 inhibition (TLR4i): cells were infected with TLR4-siRNA-lentivirus; HDAC inhibition (HDACi): cells were treated with HDAC inhibitor TSA; TLR4 inhibition+LPS challenge (TLR4i+LPS): cells were infected with TLR4-siRNA-lentivirus, followed by LPS challenge; HDAC inhibition+LPS challenge (HDACi +LPS): cells were treated with TSA, followed by LPS challenge; Thy-1 inhibition (Thy-1 siRNA): cells were infected with Thy-1-siRNA-lentivirus; Thy-1 overexpression (Thy-1 OE): cells were infected with Thy-1-OE-lentivirus; Thy-1 overexpression+LPS challenge (Thy-1 OE+LPS): cells were infected with Thy-1-OE-lentivirus, followed by LPS challenge.

\section{MTT Assay}

Cell proliferation was assessed by a modified 3-(4,5Dimethylthiazol-2-yl)-2,5-diphenyltetrazolium bromide (MTT) assay. Cells in exponential growth were plated at a concentration of $2 \times 10^{3}$ cells/well in 96-well culture plates the day before drug treatment. Following drug treatment, $10 \mu \mathrm{l}$ MTT $(10 \mathrm{mg} / \mathrm{ml})$ was added and incubated for $4 \mathrm{~h}$. The reaction was terminated by removal of the supernatant and addition of $150 \mu \mathrm{l}$ DMSO for $30 \mathrm{~min}$. Optical density (OD) of each well was measured at $490 \mathrm{~nm}$ using an ELISA reader (ELx808 Bio-Tek Instruments, USA).

\section{BrdU Assay}

Cell proliferation was measured by BrdU assay in cells infected with Thy-1-OE-lentivirus or Thy-1-siRNA-lentivirus according to the manufacturer's instructions (Cell Signaling Technology) as described in our previous study. ${ }^{10}$ DNA synthesis was quantified by the magnitude of OD at $450 \mathrm{~nm}$.

\section{Flow Cytometry Assay}

Flow cytometry was performed to assess the relative percentages of cells at different phases in the cell cycle. At $72 \mathrm{~h}$ after LPS stimulation, cells were harvested, fixed in $70 \%$ alcohol for $1 \mathrm{~h}$ at $4^{\circ} \mathrm{C}$, permeabilized with PBS containing $0.2 \%$ Tween-20 at $37^{\circ} \mathrm{C}$ for $15 \mathrm{~min}$, and incubated in PBS with $50 \mu \mathrm{g} / \mathrm{ml}$ propidium iodide (P4170, Sigma, USA) and $10 \mu \mathrm{g} / \mathrm{ml} \mathrm{RNase}$ (EN0531, Fermentas, CA) for $1 \mathrm{~h}$ at $37^{\circ} \mathrm{C}$. The fluorescence of $10^{6}$ cells was analyzed on BD FACSCalibur instruments (BD Biosciences, USA). G1, S, and G2/M ratios were calculated using CellQuest Pro Software (version 5.1, BD Biosciences).

\section{Real-Time PCR}

To determine TLR4, HDAC- 4 , -5 , and -7 , and Thy- 1 mRNA expression, total RNA was extracted from cells using Trizol reagent and the RNeasy kit (Invitrogen), followed by reverse transcription using M-MLV polymerase (Promega, USA). Real-time PCR was performed using sequence-specific primers as listed in Table 1. Amplification was performed on the IQ5 PCR System (Bio-Rad, USA) with an initial denaturing step at $95^{\circ} \mathrm{C}$ for $15 \mathrm{~s}, 45$ cycles of denaturing at $95^{\circ} \mathrm{C}$ for $5 \mathrm{~s}$, and annealing at $60^{\circ} \mathrm{C}$ for $30 \mathrm{~s}$. Thy- 1 gene expression, which was normalized to GAPDH expression, was analyzed by the $\Delta \Delta \mathrm{Ct}$ method. ${ }^{13}$

\section{Western Blot Analysis}

Cells were lysed on ice with RIPA lysis buffer $(50 \mathrm{mM}$ Tris- $\mathrm{HCl}, \mathrm{pH}$ 7.4, $150 \mathrm{mM} \mathrm{NaCl}, 1 \%$ Nonidet P-40, $0.5 \%$ deoxycholic acid, $0.1 \%$ sodium dodecyl sulfate (SDS), $5 \mathrm{mM}$ EDTA, $2 \mathrm{mM}$ phenylmethylsulfonyl fluoride (PMSF), $20 \mu \mathrm{g} / \mathrm{ml}$ aprotinin, $20 \mu \mathrm{g} / \mathrm{ml}$ leupeptin, $10 \mu \mathrm{g} / \mathrm{ml}$ pepstanin A, and $150 \mathrm{mM}$ benzamidine) for $15 \mathrm{~min}$. Supernatants were collected after centrifugation and protein quantification was determined using the BCA method. Equal amount of total proteins were resolved by SDS-polyacrylamide gel electrophoresis, transferred to polyvinylfluoride membranes, and incubated with the appropriate primary and secondary antibodies. Signals were detected using the ECL Plus Western blotting system kit (Amersham, USA). The results of immunoblotting were recorded with the Perfection 3490 photo gel imaging systems (Epson, Japan) and analyzed with Image Pro PLUS Media Cybernetics (Rockville, MD, USA). The expression level of target proteins was normalized to GAPDH.

\section{HDAC Activity Assay}

HDAC activity in lung fibroblasts after different treatments was determined by a HDAC Activity Assay Kit (KA0787,

Table 1 The sequence-specific primers used for real-time PCR

\begin{tabular}{ll}
\hline Description & sequence \\
\hline GAPDH-F: & 5'-ATCACTGCCACCCAGAAG-3' \\
GAPDH-R: & 5'-TCCACGACGGACACATTG-3' \\
TLR4-F: & 5'-GCCGTTGGTGTATCTTTG-3' \\
TLR4-R: & 5'-GCTGTTGGCTCAGGATTC-3' \\
HDAC-4-F: & 5'-CTGCAAGTGGCCCCTACAG-3' \\
HDAC-4-R: & 5'-CTGCTCATGTGACGCTGGA-3' \\
HDAC-5-F: & 5'-AGCACCGAGGTAAAGCTGAG-3' \\
HDAC-5-R: & 5'-GAACTCTGGTCCAAAGAAGCG-3' \\
HDAC-7-F: & 5'-TTCCTGGCAGGCTTACACC-3' \\
HDAC-7-R: & 5'-ATGGACTGTTCTCTCAAGGGC-3' \\
Thy-1-F: & 5'-GCCGCCATGAGAATAACA-3' \\
Thy-1-R: & 5'-GCTAGGGTAAGGACCTTGAT-3'
\end{tabular}



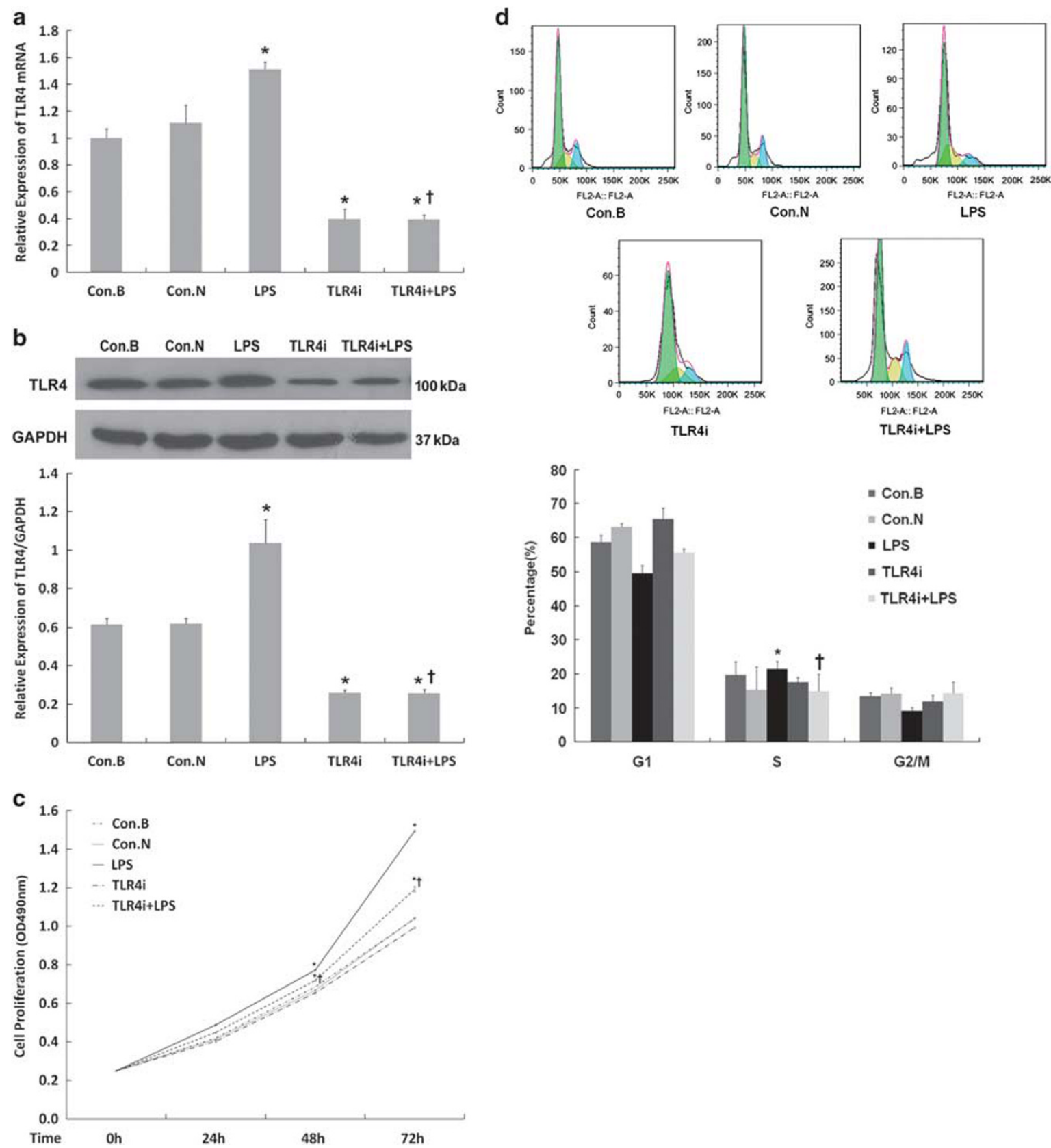

Figure 1 LPS/TLR4 induced the proliferation of lung fibroblast. The effect of siRNA-mediated TLR4 depletion $\left(1 \times 10^{8} \mathrm{TUs} / \mathrm{ml}\right.$ for $\left.48 \mathrm{~h}\right)$ on the expression of TLR4 mRNA and protein in lung fibroblasts $72 \mathrm{~h}$ after LPS challenge as determined by real-time PCR (a) and western blot (b), respectively. Cell proliferation (viability) and cell cycle of lung fibroblasts at $0,24,48$, and $72 \mathrm{~h}$ after LPS challenge was detected by MTT assay (c) and flow cytometry (d, $72 \mathrm{~h}$ after LPS challenge). Blots are representative of three independent experiments. Columns represent mean values and error bars represent s.d. Points represent mean values and error bars represent s.d. ${ }^{*} P<0.05$ compared with the Con. $\mathrm{N}$ group at the same time point. ${ }^{\dagger} P<0.05$ compared with the LPS group at the same time point.

Figure 2 HDACs were upregulated and activated by LPS challenge through TLR4. The effect of LPS/TLR4 on HDAC-4, -5, and -7 expression and activation in lung fibroblasts was detected by real-time PCR (a-c), western blot analysis (d-f), and HDAC activity assay (g) at $72 \mathrm{~h}$ after LPS challenge. TLR4-siRNA-lentivirus was used to inhibit the expression of TLR4. HDAC inhibitor TSA was used to inhibit the activation of HDACs in lung fibroblasts. Blots are representative of three independent experiments. Columns represent mean values and error bars represent s.d. ${ }^{*} P<0.05$ compared with the Con. $\mathrm{N}$ group. ${ }^{\dagger} P<0.05$ compared with the LPS group. 


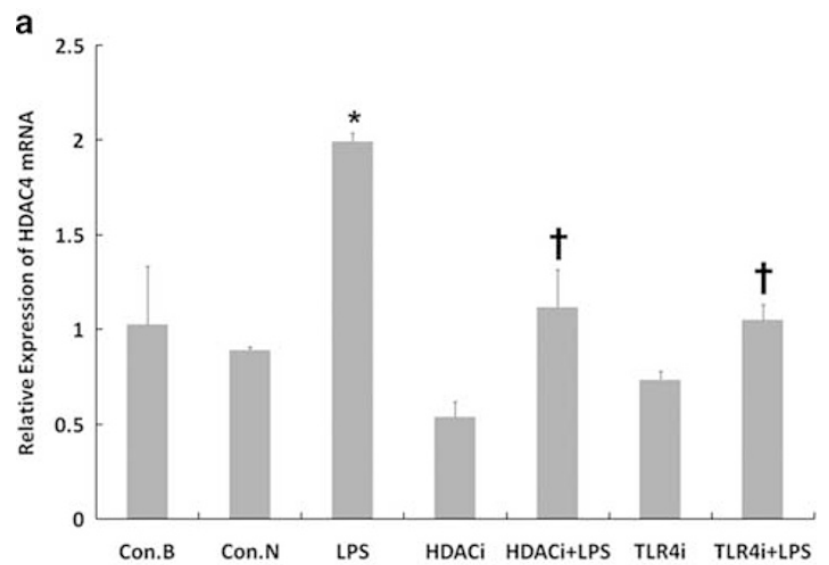

b
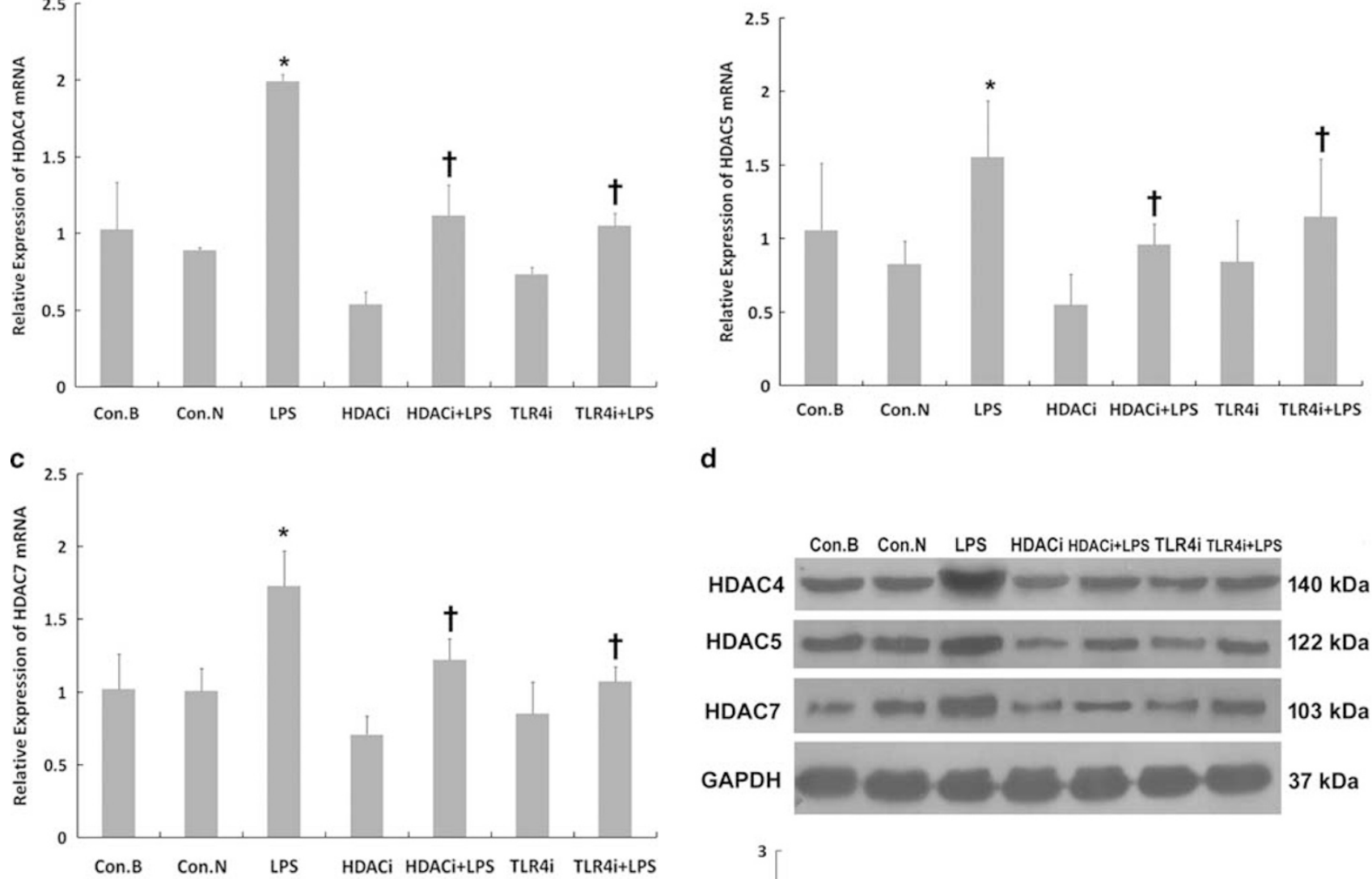

d
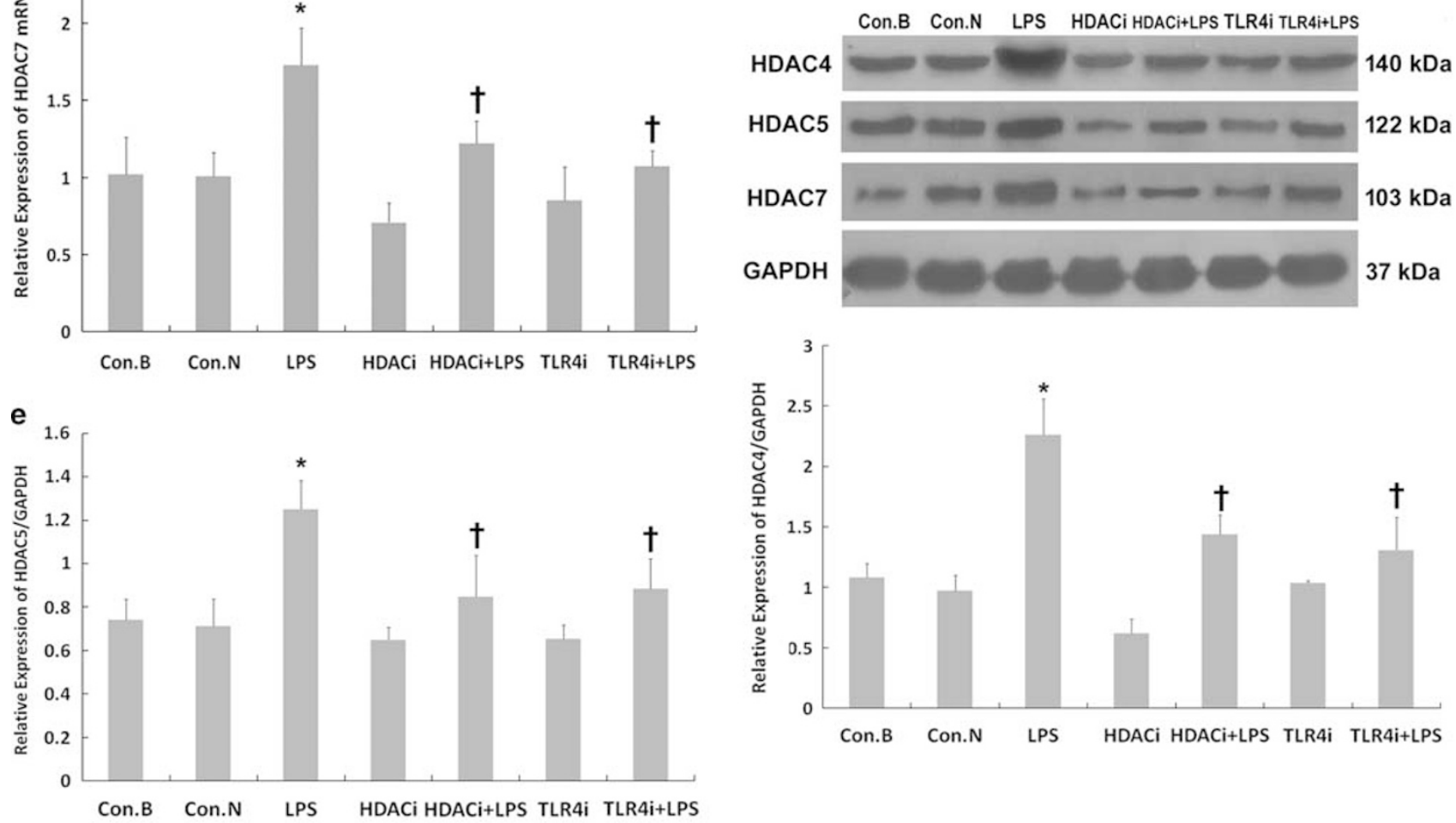

f
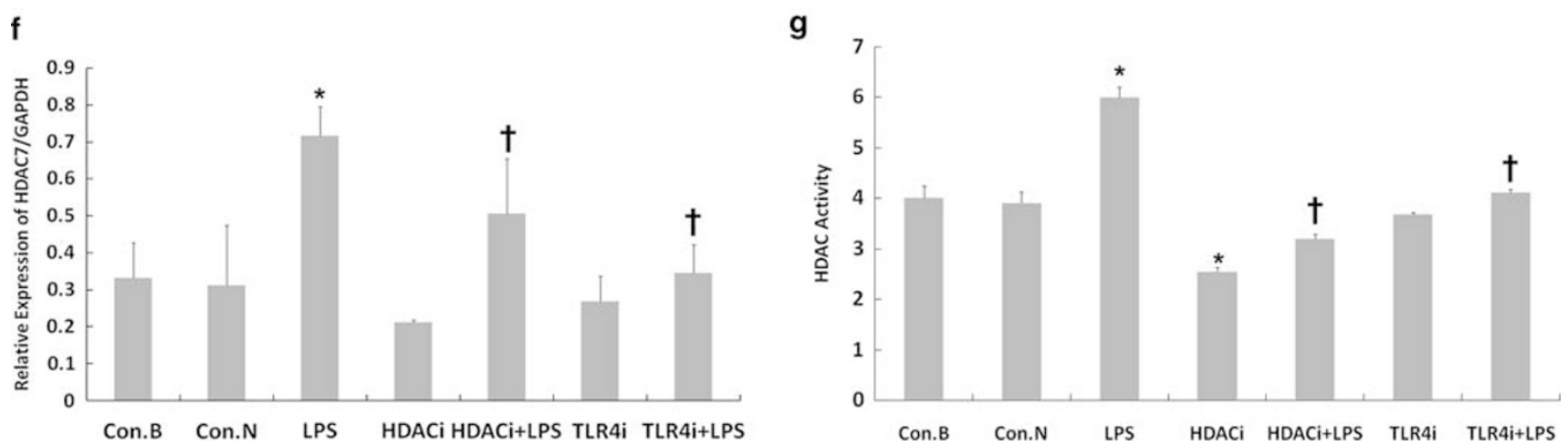
Abnova, Taiwan). Briefly, an aliquot of nuclear extracts $\left(30 \mu \mathrm{g}\right.$ ) was added to $\mathrm{ddH}_{2} \mathrm{O}$ (final volume $85 \mu \mathrm{l}$ ) in each well. As a positive control, $2 \mu \mathrm{l}$ of HeLa nuclear extract with $83 \mu \mathrm{l}$ $\mathrm{ddH}_{2} \mathrm{O}$ was used. Then, $10 \mu \mathrm{l}$ of $10 \times$ HDAC Assay Buffer and $5 \mu \mathrm{l}$ of HDAC fluorometric substrate were added to each well and incubated at $37^{\circ} \mathrm{C}$ for $30 \mathrm{~min}$, followed by addition of $10 \mu \mathrm{l}$ of Lysine Developer and incubation at $37^{\circ} \mathrm{C}$ for $30 \mathrm{~min}$. Fluorescence was obtained by plate reader $(\mathrm{Ex} .=350-380 /$ $440-460 \mathrm{~nm})$. HDAC activity was expressed as the relative fluorescence units per $\mu \mathrm{g}$ protein sample.

\section{Chromatin Immunoprecipitation}

Chromatin immunoprecipitation (ChIP) assay was performed to analyze the histone modification of acetylated $\mathrm{H} 4$ (Ace-H4) associated with the promoter region of the Thy-1 gene. Immunoprecipitation was performed using SimpleChIP Enzymatic Chromatin IP Kit (9003, Cell Signaling Technology) with ChIP-grade antibodies against HDAC-4 (7628; Cell Signaling Technology), RNA polymerase II, or IgG control, according to the manufacture's protocol. DNA was eluted and purified, followed by PCR amplification using primers specific for Thy-1 promoter: forward primer: 5'-GAAACCA AGAGAATCTCC-3' and reverse primer: 5'-GCCTGCCTG TTCTCCTAT- ${ }^{\prime}$.

\section{Cellular Immunofluorescent Assay}

Cells were fixed with $4 \%$ paraformaldehyde for $15 \mathrm{~min}$, washed three times with PBS for $10 \mathrm{~min}$, and incubated with blocking buffer (PBS containing 3\% of BSA and $0.1 \%$ Triton$\mathrm{X} 100$ ) at room temperature for $30 \mathrm{~min}$. Primary anti-Thy-1 (ab225; Abcam, UK) diluted in blocking buffer (1:200) was added and incubated at room temperature for $1 \mathrm{~h}$. Then, cells were washed with PBS containing 0.1\% Triton-X 100 and incubated with Alexa Fluor 488-conjugated goat anti-rabbit IgG (Abcam, USA) at room temperature for $1 \mathrm{~h}$, followed by washing three times with PBS containing $0.1 \%$ Triton-X 100. The nuclei were stained with $0.5 \mu \mathrm{mol} / \mathrm{l}$ of hoechst 33342 (Life Technologies, USA) and images were captured by a fluorescence microscope (BX-41, Olympus, Japan).

\section{Statistical Analysis}

All data are represented as mean \pm s.d. SPSS software (version 12.0) was used to compare mean values of single-factor multiple samples. The homogeneity of variance data was analyzed with the one-factor analysis of variance least squares difference (LSD) test, and the heterogeneity of variance data was analyzed with the Kruskal-Wallis rank-sum test. Statistical significance was defined as $P<0.05$.

\section{RESULTS}

\section{Silencing of TLR4 Inhibits LPS-Enhanced Proliferation of Lung Fibroblasts}

To investigate the effects of TLR4 on the proliferation of lung fibroblasts upon LPS challenge, we first infected mouse lung fibroblasts (MIC-CELL-0040) with TLR4-siRNA-lentivirus to knock down TLR4 and determined the TLR4 mRNA and protein expression by real-time PCR and western blot, respectively. TLR4 mRNA (Figure 1a) and protein (Figure 1b) levels were significantly reduced in lung fibroblasts after infection with $1 \times 10^{8} \mathrm{TUs} / \mathrm{ml}$ TLR4-siRNA-lentivirus for $48 \mathrm{~h}$. Challenge of lung fibroblasts with LPS led to significant upregulation of TLR4 mRNA and protein expression $(P<0.05)$; however, pretreatment with TLR4-siRNA-lentivirus followed by LPS challenge still decreased the TLR4 mRNA and protein to levels of TLR4-siRNA-lentivirus infection alone $(P<0.05)$, indicating that TLR4 is a downstream target of LPS signaling pathway and providing an additional evidence for the notion that TLR4 plays an important role in LPS-induced proliferation of primary cultured mouse lung fibroblasts. ${ }^{10,14}$ To extend these observations, we further measured cell proliferation and cell-cycle progression of lung fibroblasts after TLR4 silencing in the presence or absence of LPS challenge for different time points by MTT assay and flow cytometry, respectively. Compared with controls, LPS significantly increased lung fibroblast proliferation (Figure 1c) and the number of cells in the $S$ phase (Figure 1d) 48-72 h after challenge $(P<0.05)$. Both effects were abolished by TLR4-siRNA-lentivirus infection $(P<0.05)$. These data suggest that TLR4 is required for the LPS-enhanced proliferation of lung fibroblasts.

\section{HDACs Are Upregulated and Activated by LPS through TLR4}

It was recently reported that HDACs, such as HDAC-7, promote TLR4-mediated growth of macrophages. ${ }^{15}$ To test whether LPS/TLR4 promotes the proliferation of lung fibroblasts via HDACs, we determined the effect of LPS/TLR4 on HDAC-4, -5 , and -7 expression and activation in lung fibroblasts. We infected lung fibroblasts with TLR4-siRNAlentivirus or treated cells with HDAC inhibitor TSA in the presence or absence of LPS challenge for different time points and assessed the HDAC-4, -5 , and -7 mRNA and protein expression by real-time PCR and western blot, respectively. HDAC activity assays were used to detect the activity of HDAC-4, -5, and -7. In comparison with controls, LPS challenge for $72 \mathrm{~h}$ resulted in a significant increase in mRNA levels of HDAC-4 (Figure 2a), HDAC-5 (Figure 2b), and HDAC-7 (Figure 2c). HDAC inhibitor TSA abolished the stimulation of the expression of HDAC-4, -5, and -7 (Figure 2a-c). Interestingly, similar to TSA, TLR4-siRNA-lentivirus also significantly inhibited an increase in the expression of HDAC-4, -5 , and -7 by LPS (Figure $2 \mathrm{a}-\mathrm{c}$ ). Consistent with the alteration of mRNA levels, LPS robustly increased the protein levels of HDAC-4 (Figure 2d), HDAC-5 (Figure 2d and e), and HDAC-7 (Figure 2d and f), all of which were abolished by either TSA or TLR4-siRNA-lentivirus (Figure 2d-f, $P<0.05)$. Consequently, LPS increased the activity of HDACs that was prevented by either TSA or TLR4-siRNA-lentivirus (Figure 2g, $P<0.05$ ). These results indicate that TLR4 mediates LPS-induced upregulation and activation of HDACs. 


\section{HDACs Mediate LPS-Induced Histone Deacetylation in Lung Fibroblasts}

To investigate the effect of HDACs on LPS-induced histone deacetylation in lung fibroblasts, we applied HDAC inhibitor
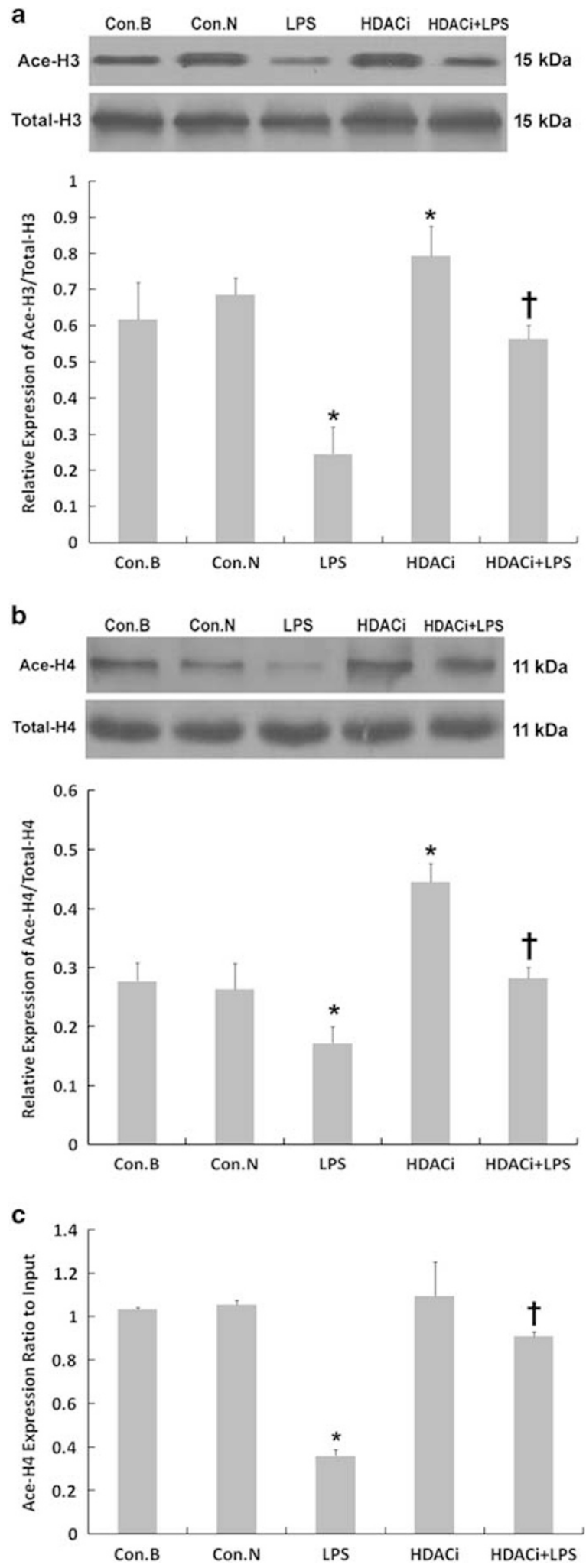

TSA to inhibit the activation of HDACs and measured Ace-H3 and Ace-H4, as well as total $\mathrm{H} 3$ and $\mathrm{H} 4$ levels in lung fibroblasts at $72 \mathrm{~h}$ after LPS challenge by western blot analysis. There was a LPS-mediated decrease in both Ace-H3 (Figure 3a) and Ace-H4 (Figure 3b) when compared with the non-LPS-challenged cells $(P<0.05)$. HDAC inhibitor TSA prevented the LPS-mediated decrease in protein levels of Ace-H3 and Ace-H4 (Figure 3, P<0.05). Interestingly, compared with vehicle control, there was a slight increase in Ace-H3 and Ace-H4 in cells pretreated with TSA without LPS challenge (HDACi group), indicating that inhibition of HDACs alone increases the acetylation of $\mathrm{H} 3$ and $\mathrm{H} 4$ in lung fibroblasts.

\section{LPS Promotes Histone Deacetylation via HDACs at the Thy-1 Promoter Region in Lung Fibroblasts}

Ace-H4 has been identified as a marker for active chromatin structure. Enriched Ace-H4 is associated with open chromatin structure and was found to be related to the transcriptional activation of Thy- $1 .{ }^{16}$ To investigate the mechanisms underlying the reduction of Ace-H4 in response to LPS challenge, we used HDAC inhibitor TSA to inhibit the activation of HDACs and examined Ace-H4 in the promoter region of the Thy- 1 gene by ChIP assay. As shown in Figure 3c, LPS decreased the amount of precipitated DNA associated with Ace-H4 at the Thy-1 promoter region when compared with the cells from control group $(P<0.05)$, whereas pretreatment with HDAC inhibitor TSA significantly restored association of Ace-H4 with the Thy-1 promoter DNA $(P<0.05)$. These results indicate that Ace- $\mathrm{H} 4$ at the Thy- 1 promoter region is decreased in response to LPS challenge through activation of HDACs, and suggest that HDACs could mediate LPS-induced epigenetic silence of Thy-1 gene.

\section{LPS Downregulates the Expression of Thy-1 Through HDACs in Lung Fibroblasts}

To evaluate the effect of LPS challenge on HDACs and Thy-1 expression in lung fibroblasts, we used HDAC inhibitor TSA to inhibit the activation of HDACs and determined the Thy-1 mRNA and protein levels by real-time PCR, western blot, and cellular immunofluorescent assays. LPS significantly decreased the level of Thy-1 mRNA, whereas TSA increased

Figure 3 HDACs mediated LPS-induced histone deacetylation in lung fibroblasts. Histone deacetylation in lung fibroblasts $72 \mathrm{~h}$ after LPS challenge was assessed according to the expression of Ace- $\mathrm{H} 3$ versus Total-H3 (a) and Ace-H4 versus Total-H4 (b), as detected by western blotting. Histone deacetylation presented by Ace-H4 (c) in the Thy-1 gene promoter region in lung fibroblasts at $72 \mathrm{~h}$ after LPS challenge was detected by the quantitative ChIP assay. The effect of HDACs on LPSinduced histone deacetylation was evaluated by pretreatment of HDAC inhibitor TSA. Blots are representative of three independent experiments. Columns represent mean values and error bars represent s.d. ${ }^{*} P<0.05$ compared with the Con. $\mathrm{N}$ group. ${ }^{\dagger} P<0.05$ compared with the LPS group. 

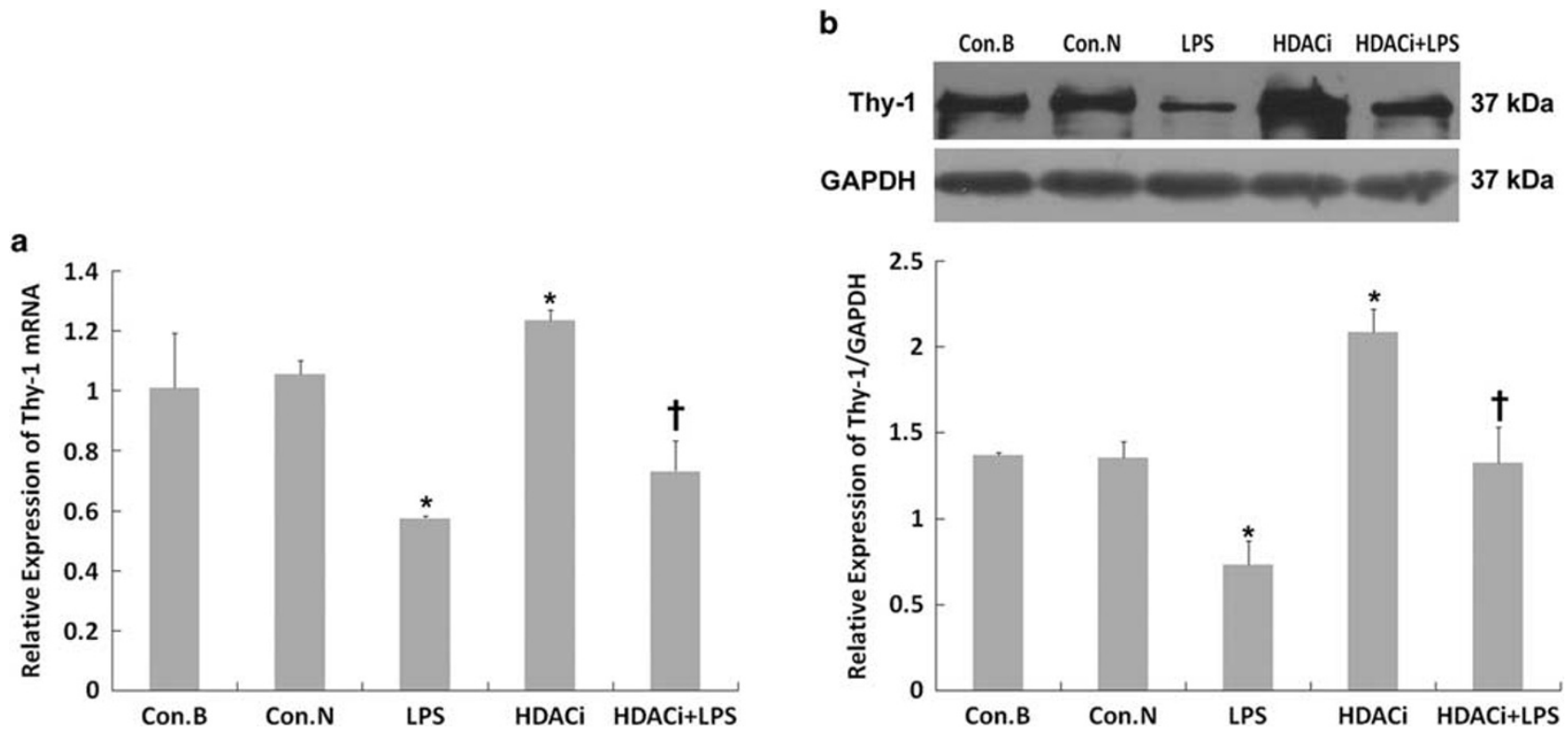

Con.B
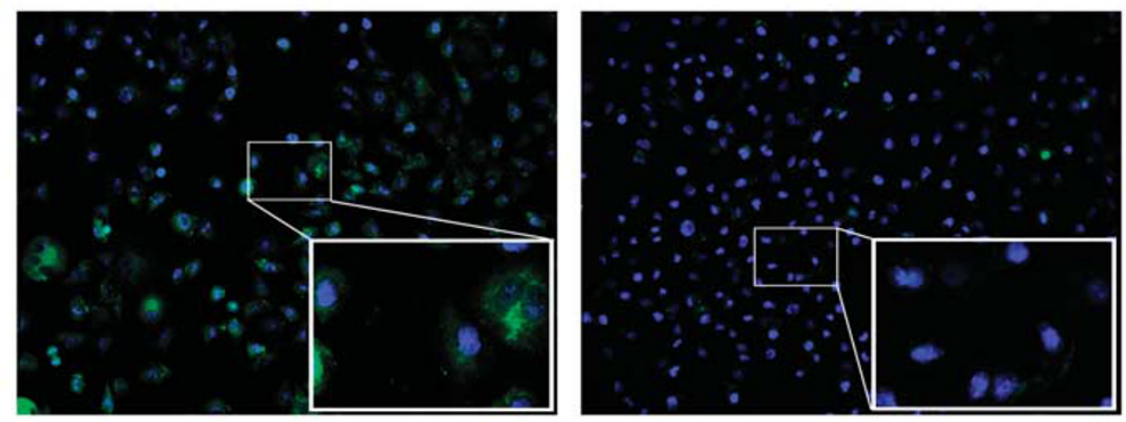

Con.N

LPS

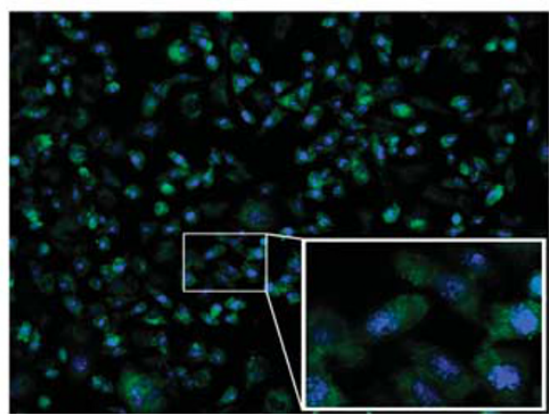

HDACi

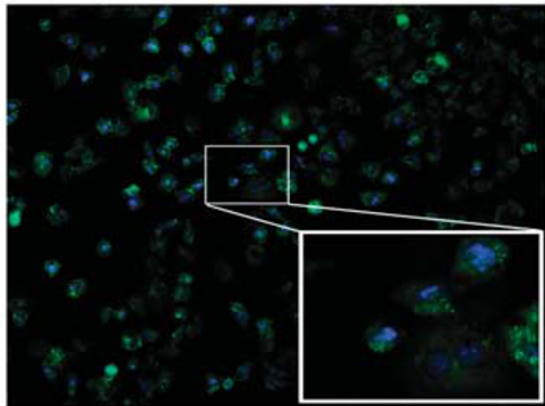

HDACi+LPS

Figure 4 HDACs mediated LPS-induced Thy-1 downregulation in lung fibroblasts. To test the effect of HDACs on the expression of Thy-1 mRNA and protein in lung fibroblasts at $72 \mathrm{~h}$ after LPS challenge, HDAC inhibitor TSA was used to inhibit the activation of HDACs. Real-time PCR (a), western blot (b), and cellular immunofluorescent assay $(\mathbf{c}, \times 400)$ were applied to detect Thy-1mRNA and protein expression in lung fibroblasts. Blots are representative of three independent experiments. Columns represent mean values and error bars represent s.d. ${ }^{*} P<0.05$ compared with the Con. $\mathrm{N}$ group. ${ }^{\dagger} P<0.05$ compared with the LPS group. The higher magnification insert was displayed at the bottom right corner in (c).

the level of Thy-1 mRNA (Figure $4 \mathrm{a}, P<0.05$ ). Furthermore, LPS significantly decreased Thy-1 protein level, whereas TSA increased the levels of Thy-1 protein and inhibited the decrease of Thy-1 mRNA expression in response to LPS treatment (Figure $4 \mathrm{~b}, P<0.05)$. Similar results were observed in immunofluorescent assays (Figure 4c). These findings indicate that inhibition of HDACs increases the expression of Thy-1 in lung fibroblasts. 


\section{HDACs Mediate LPS-Induced Lung Fibroblast Proliferation}

To investigate the effect of HDACs on LPS-induced lung fibroblast proliferation during different cell-cycle stages, we used HDAC inhibitor TSA to inhibit the activation of HDACs and measured the cell proliferation and cell-cycle progression of lung fibroblasts at different time points after LPS challenge using the MTT assay and flow cytometry. Compared with time-matched controls, LPS challenge resulted in enhanced cell proliferation (Figure 5a) and accumulation of cells in the $S$ phase (Figure $5 b, P<0.05$ ) that were prevented by TSA pretreatment $(P<0.05)$. Interestingly, compared with control groups, in the absence of LPS challenge, there was a significant decrease in cell proliferation and the number of cells in the S phase following pretreatment with TSA (HDACi group). These data indicate that inhibition of HDACs may inhibit the proliferation of lung fibroblasts.

\section{Overexpression of Thy-1 Reduces LPS-Induced Lung Fibroblast Proliferation}

To evaluate the function of Thy-1 in LPS-induced lung fibroblast proliferation, we down- or upregulated Thy-1 gene expression through infecting cells with Thy-1-siRNAlentivirus or Thy-1-OE-lentivirus. Real-time PCR and western blot showed that both mRNA (Figure 6a) and protein (Figure 6b) levels of Thy-1 in lung fibroblasts were significantly reduced after Thy-1-siRNA-lentivirus infection, whereas they increased after Thy-1-OE-lentivirus infection. Moreover, as shown in Figure 6c, BrdU assay showed that silencing Thy-1 gene by Thy-1-siRNA-lentivirus (Thy-1 siRNA group) could promote lung fibroblast proliferation even in the absence of LPS $(P<0.05)$. Conversely, overexpressing Thy- 1 gene by Thy-1-OE-lentivirus (Thy-1 OE group) could inhibit lung fibroblast proliferation and reduce LPS-induced lung fibroblast proliferation (Thy-1 OE+LPS group, $P<0.05)$. These results indicate that expression of Thy-1 gene is negatively correlated with lung fibroblast proliferation and silencing of Thy-1 gene may contribute to LPS-induced lung fibroblast proliferation.

\section{DISCUSSION}

In this study, we found that LPS promoted the proliferation of primary cultured mouse lung fibroblasts, accompanied with increased expression of HDAC-4, -5 , and -7 , and decreased Ace-H3 and Ace-H4. Moreover, using ChIP analysis, we discovered that LPS decreased the association of Ace-H4 at the Thy- 1 promoter and hence reduced Thy- 1 gene expression. In addition, using lentivirus-delivered shRNA to silence TLR4, we found that silencing of TLR4 prevented LPSmediated expression or activation of HDACs and promotion of cell proliferation. By pharmacologic inhibition of HDACs, we discovered that inhibition of HDACs efficiently prevented LPS-mediated promotion of cell proliferation, upregulation of HDAC-4, -5, and -7 , deacetylation of histones $\mathrm{H} 3$ and $\mathrm{H} 4$, and downregulation of Thy-1. Furthermore, through lentivirus-based RNAi or gene overexpression technology, we revealed that expression of Thy-1 gene is negatively
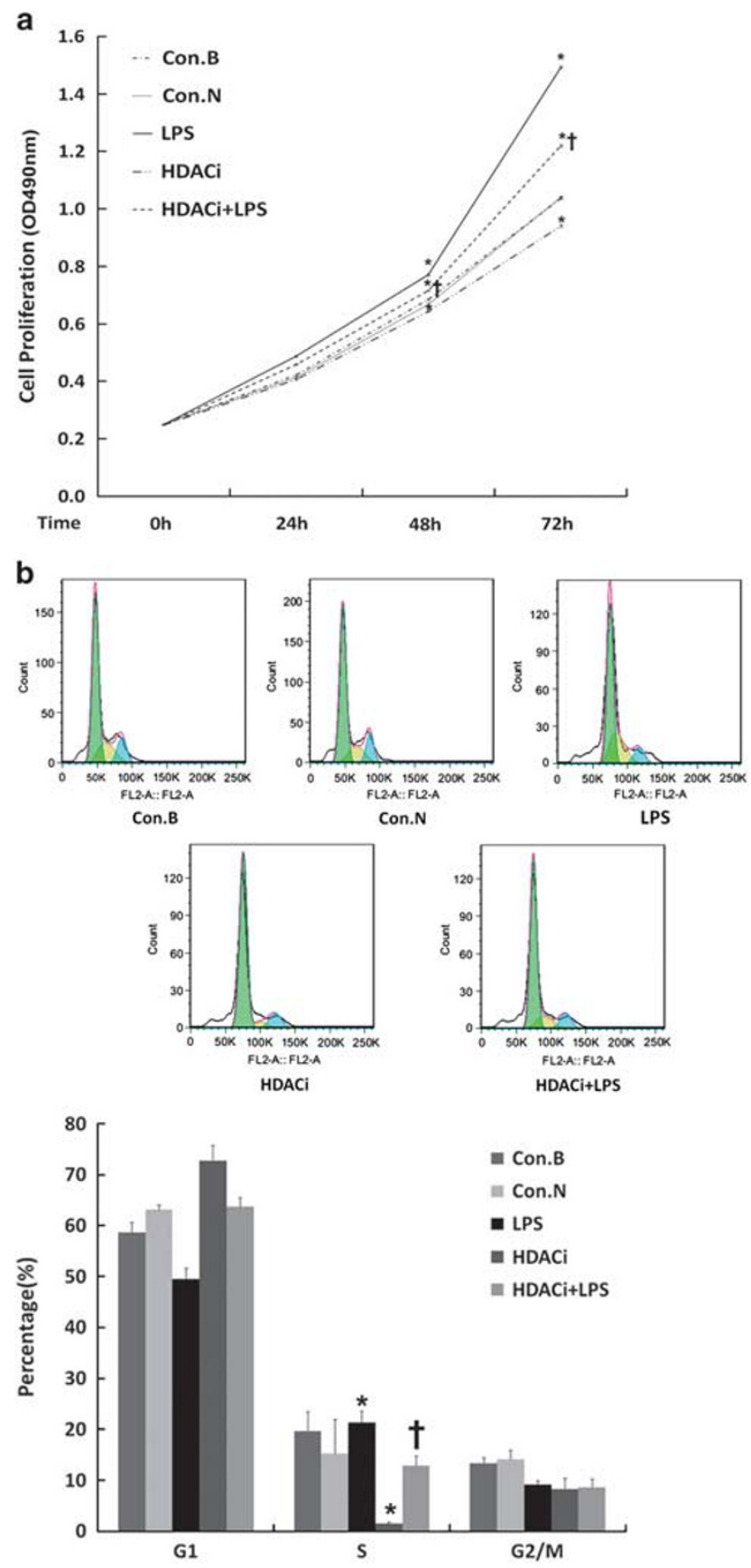

Figure 5 LPS-induced lung fibroblast proliferation depended on HDACs. The effect of HDACs on the proliferation of lung fibroblasts $72 \mathrm{~h}$ after LPS challenge was detected through pretreatment of HDAC inhibitor TSA. Cell proliferation (viability) and cell cycle of lung fibroblasts at $0,24,48$, and $72 \mathrm{~h}$ after LPS challenge was detected by MTT assay (a) and flow cytometry (b). Blots are representative of three independent experiments. Columns represent mean values and error bars represent

s.d. Points represent mean values and error bars represent s.d. ${ }^{*} P<0.05$ compared with the Con. $\mathrm{N}$ group at the same time point. ${ }^{\dagger} P<0.05$ compared with the LPS group. 

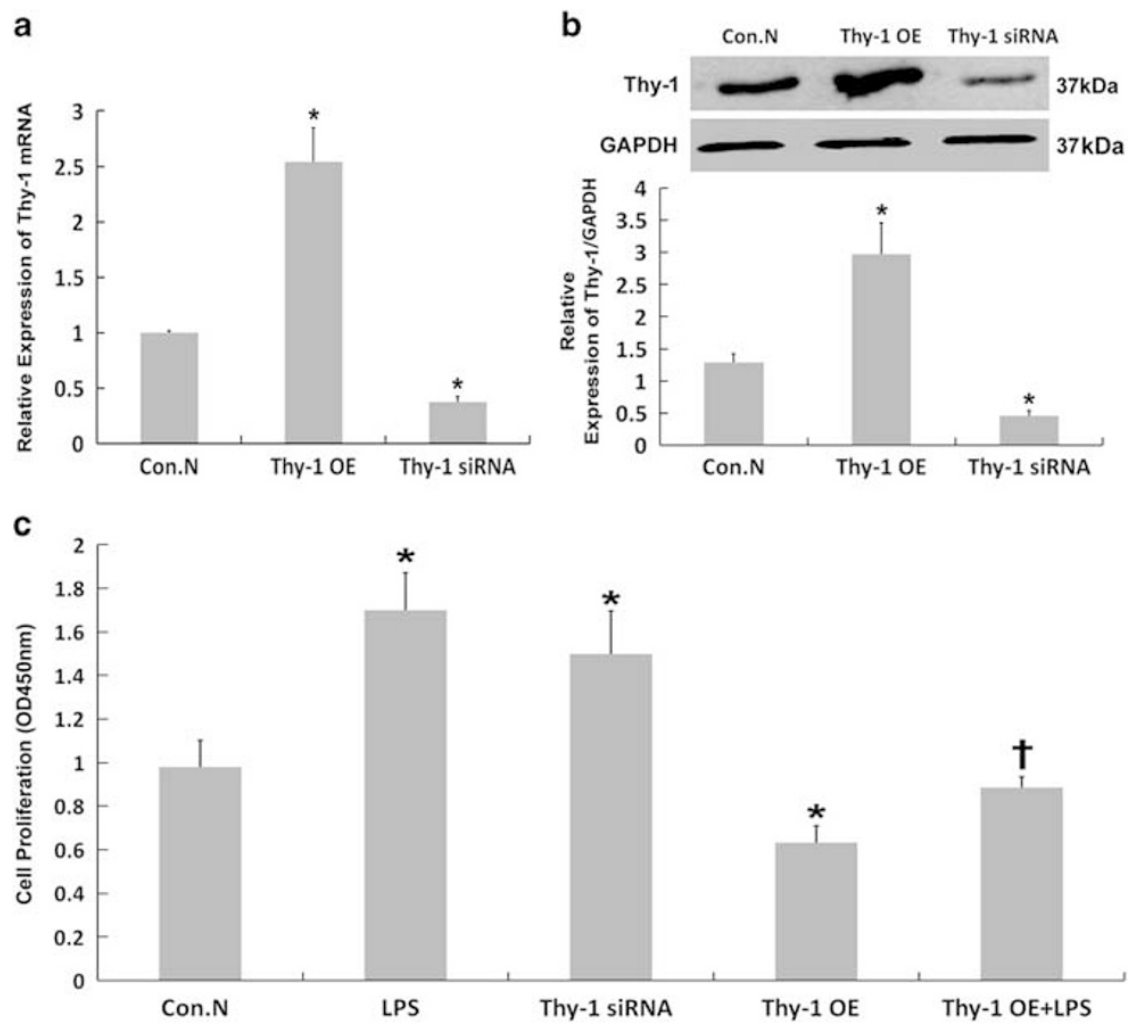

Figure 6 Alteration of Thy-1 gene expression influenced lung fibroblast proliferation in the presence or absence of LPS challenge. Thy-1-siRNA-lentivirus or Thy-1-OE-lentivirus was applied to silence or overexpress Thy-1 in lung fibroblast, respectively. The expression of Thy-1 mRNA and protein was determined by real-time PCR (a) and western blot (b), respectively. Cell proliferation was detected by BrdU assay (c) in cells infected with Thy-1-siRNAlentivirus or Thy-1-OE-lentivirus following LPS challenge for $72 \mathrm{~h}$. Blots are representative of three independent experiments. Columns represent mean values and error bars represent s.d. ${ }^{*} P<0.05$ compared with the Con. $\mathrm{N}$ group. ${ }^{\dagger} P<0.05$ compared with the LPS group.

correlated with lung fibroblast proliferation and silencing of Thy-1 gene may contribute to LPS-induced lung fibroblast proliferation. Our data suggest that LPS-TLR4 signaling upregulates and activates HDACs that in turn leads to deacetylation of histones $\mathrm{H} 3$ and $\mathrm{H} 4$ at the Thy- 1 gene promoter region and concomitant Thy- 1 gene silencing and proliferation of lung fibroblasts (as summarized in Figure 7).

Histone deacetylation-associated epigenetic regulation is critical in LPS-induced Thy-1 gene silencing in lung fibroblasts and cell proliferation. As the specific receptor of LPS, TLR4 plays a critical role in LPS-induced ALI and pulmonary fibrosis. Previous studies have shown that TLR4 is required for LPS-associated lung fibroblast activation ${ }^{12}$ and proliferation, ${ }^{14,17}$ lung inflammatory reaction, ${ }^{18,19}$ and pulmonary fibrosis. ${ }^{1}$ In agreement with these published findings, our present study demonstrated that upregulation of TLR4 by LPS accounted for LPS-induced proliferation in mouse lung fibroblasts (MIC-CELL-0040) that could be restored by siRNA-mediated TLR4 silencing, suggesting that TLR4 is essential for LPS-induced Thy-1 gene silencing in lung fibroblasts and cell proliferation. Further experiments are needed to confirm the role of TLR4 in lung fibroblast proliferation with TLR4 knockout cells.
HDACs play important roles in histone modificationrelated epigenetic regulation of expression of various genes, including Thy- 1 . The HDAC family includes 18 members of four classes. HDAC-4, $-5,-6,-7,-9$, and -10 belong to class II. ${ }^{20}$ LPS has been reported to regulate proinflammatory gene expression in macrophages by inducing expression of HDAC$-4,-5$, and -7 at the mRNA level. ${ }^{21}$ LPS has also been reported to induce HDAC activity in human lung microvascular endothelial cells. ${ }^{22}$ HDAC-7 could promote TLR4-dependent proinflammatory gene expression in macrophages. ${ }^{15}$ Accordingly, HDAC inhibitor TSA could specifically inhibit LPSdependent gene expression in inflammatory macrophages ${ }^{23}$ or epithelial cells. ${ }^{24}$ TSA was also reported to suppress cell proliferation and epithelial-mesenchymal transition through inactivation of the component of LPS/TLR4 signaling pathway, such as phosphatidylinositol-3-kinase (PI3K)/Akt, p38 mitogen-activated protein kinase (MAPK), and extracellular signal-regulated kinase(ERK) $1 / 2$ pathways. ${ }^{25,26}$ Meanwhile, Sato et $a l^{27}$ reported that inhibition of HDACs with TSA in human choriodecidual explants led to a massive increase in LPS-stimulated interleukin (IL)- $1 \beta$, indicating that HDACs can also negatively regulate the expression of some target genes. In our present study, by means of TLR4-siRNA- 
a
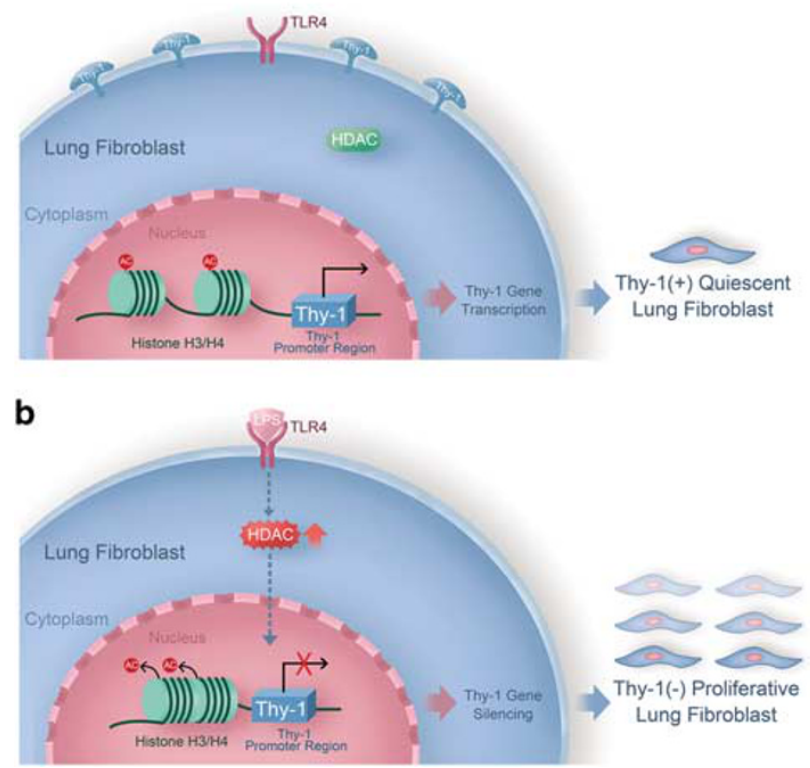

Figure 7 Schema graph of histone deacetylation-associated epigenetic regulation of LPS/TLR4-induced Thy-1 gene silencing and lung fibroblasts proliferation. In normal Thy-1 (+) lung fibroblasts (a), acetylation of histones $\mathrm{H} 3$ and $\mathrm{H} 4$ enhances accessibility of chromatin and allows DNAbinding proteins to interact with exposed sites to activate Thy-1 gene transcription. In LPS-challenged lung fibroblasts (b), LPS may activate HDACs through TLR4 that in turn results in histone $\mathrm{H} 3$ and $\mathrm{H} 4$ deacetylation and tight wrapping of the DNA around the histone cores, making it harder for transcription factors to bind to the DNA at the Thy-1 gene promoter region that contributes to Thy- 1 gene silencing and lung fibroblast proliferation.

lentivirus infection, we further demonstrated that LPS stimulated the expression and activation of HDAC-4, -5, and -7 through TLR4, implying that the TLR4-mediated expression and activation of HDACs may play an important role in LPSinduced epigenetic regulation of gene expression in lung fibroblasts and phenotype transition. However, the mechanistic link between TLR4 and HDAC activity remains unknown and deserves further investigation.

Histone acetylation/deacetylation is an important mechanism of epigenetic regulation. Acetylation of histones $\mathrm{H} 3$ and H4 enhances accessibility of chromatin and allows DNAbinding proteins to interact with exposed sites to activate Thy-1 gene transcription, whereas histone $\mathrm{H} 3$ and $\mathrm{H} 4$ deacetylation makes the DNA more tightly wrapped around the histone cores, blocking the binding of transcription factors to DNA at the Thy-1 gene promoter region that contributes to Thy- 1 gene silencing. ${ }^{16}$

Several studies suggested that the absence of Thy- 1 in fibroblasts correlates with pulmonary fibrosis. ${ }^{5,9,28}$ Our previous study revealed that Thy-1-related lung fibroblast phenotype transformation was essential for LPS-induced lung fibroblast proliferation. But little is known whether the regulation of Thy-1 gene expression could influence the proliferation of lung fibroblast cells. In this study, we demonstrated that upregulation (or downregulation) of Thy-1 gene could inhibit (or promote) lung fibroblast proliferation, indicating an important role for Thy-1 gene silencing in LPS-induced lung fibroblast proliferation. Meanwhile, we noticed that the effects of Thy-1 silencing and overexpression on protein levels are modest, yet the effects on proliferation are more significant (Figure 6). Whether there exists a 'threshold' effect of Thy- 1 expression on lung fibroblast proliferation deserves further study.

LPS has been reported to epigenetically regulate expression of different genes through histone acetylation/deacetylation. For example, preventing deacetylation and maintaining DNA binding of acetyl-histone $\mathrm{H} 3$ (K9) in human lung microvascular endothelial cells (HLMVECs) could attenuate LPSmediated NF- $\kappa \mathrm{B}$-dependent gene activation. ${ }^{29}$ LPS-induced IL-8 activation in human intestinal epithelial cells was also reported to be accompanied by changes of specific histone $\mathrm{H} 3$ acetylation and methylation. ${ }^{30}$ Histone deacetylation is mainly regulated by HDACs that control gene expression by means of removing acetyl groups from lysine residues in histone molecules and is closely related to epigenetic regulation of different genes. In our previous study, we demonstrated that LPS challenge causes deacetylation of $\mathrm{H} 3$ and $\mathrm{H} 4$ and inhibition of Thy-1 gene transcription in cultured mouse lung fibroblasts, indicating that LPS may silence Thy- 1 gene through histone deacetylation at the Thy-1 gene promoter region. These data suggest that deacetylation of $\mathrm{H} 3$ and $\mathrm{H} 4$ might contribute to LPS-induced and Thy-1-related phenotype transformation in lung fibroblasts. Sanders et al ${ }^{6}$ also reported epigenetic silencing of Thy-1 by histone deacetylation at the Thy- 1 gene promoter region in lung fibroblasts. However, whether this process is mediated by HDACs is unknown. In this study, we found that inhibiting HDAC activation could restore LPS-induced deacetylation of histones $\mathrm{H} 3$ and $\mathrm{H} 4$, indicating that activation of HDACs is involved in the LPS-mediated histone modification in lung fibroblasts. In addition, we found HDAC inhibitor TSA effectively alleviated LPS-induced Thy-1 gene silencing and cell proliferation of lung fibroblasts. This finding is consistent with reports that HDAC inhibitors MS-275 and SAHA could induce growth arrest and suppress LPS-stimulated nuclear accumulation of NF- $\kappa \mathrm{B}$ p 65 in human rheumatoid arthritis synovial fibroblastic E11 cells. ${ }^{31}$ Furthermore, in the present study, we found that the effect of HDAC inhibition on blocking LPS-induced reduction of Thy-1 protein levels was more apparent at the protein level than at the level of mRNA. Moreover, LPS and HDAC inhibition seemed to disproportionately affect Thy-1 protein expression (Figure 4), implying some indefinite factors, such as posttranscriptional processes, may be involved in the regulation of Thy-1 expression. We also found that inhibition of HDAC with TSA resulted in increased acetylation of both $\mathrm{H} 3$ and $\mathrm{H} 4$, upregulation of the expression of Thy-1, and inhibition of the proliferation of 
lung fibroblasts, even in the absence of LPS, demonstrating that activation of HDACs is essential for the histone modification, phenotype transformation, and proliferation in lung fibroblasts.

Taken together, our data suggest that binding of LPS to TLR4 results in activation of HDACs that in turn promotes the deacetylation of histones $\mathrm{H} 3$ and $\mathrm{H} 4$ at the Thy- 1 gene promoter region, leading to Thy- 1 gene silencing and lung fibroblast proliferation. Our insights into HDAC-related epigenetic regulation in Thy- 1 gene expression and lung fibroblast proliferation may provide novel therapeutic strategies for pulmonary fibrosis.

\section{ACKNOWLEDGMENTS}

This research was supported by grants from the National Natural Science Foundation of China (NSFC, Nos. 81270122 and 81370178). The funders had no role in study design, data collection and analysis, the decision to publish, or preparation of the manuscript.

\section{DISCLOSURE/CONFLICT OF INTEREST}

The authors declare no conflict of interest.

1. He $Z$, Zhu $Y$, Jiang $H$. Inhibiting Toll-like receptor 4 signaling ameliorates pulmonary fibrosis during acute lung injury induced by lipopolysaccharide: an experimental study. Respir Res 2009;10:126.

2. Xia $H$, Diebold $D$, Nho $R$ et al. Pathological integrin signaling enhances proliferation of primary lung fibroblasts from patients with idiopathic pulmonary fibrosis. J Exp Med 2008;205:1659-1672.

3. Li H, Du S, Yang L et al. Rapid pulmonary fibrosis induced by acute lung injury via a lipopolysaccharide three-hit regimen. Innate Immun 2009:15:143-154.

4. Cesta MF, Ryman-Rasmussen JP, Wallace DG et al. Bacterial lipopolysaccharide enhances PDGF signaling and pulmonary fibrosis in rats exposed to carbon nanotubes. Am J Respir Cell Mol Biol 2010;43:142-151.

5. Hagood JS, Prabhakaran P, Kumbla P et al. Loss of fibroblast Thy-1 expression correlates with lung fibrogenesis. Am J Pathol 2005;167: 365-379.

6. Sanders YY, Tollefsbol TO, Varisco BM et al. Epigenetic regulation of Thy- 1 by histone deacetylase inhibitor in rat lung fibroblasts. Am J Respir Cell Mol Biol 2011;45:16-23.

7. Sanders YY, Pardo A, Selman $M$ et al. Thy-1 promoter hypermethylation: a novel epigenetic pathogenic mechanism in pulmonary fibrosis. Am J Respir Cell Mol Biol 2008;39:610-618.

8. Sanders YY, Kumbla P, Hagood JS. Enhanced myofibroblastic differentiation and survival in Thy-1(-) lung fibroblasts. Am J Respir Cell Mol Biol 2007:36:226-235.

9. Zhou Y, Hagood JS, Murphy-Ullrich JE. Thy-1 expression regulates the ability of rat lung fibroblasts to activate transforming growth factorbeta in response to fibrogenic stimuli. Am J Pathol 2004;165:659-669.

10. He Z, Wang $X$, Deng $Y$ et al. Epigenetic regulation of Thy- 1 gene expression by histone modification is involved in lipopolysaccharideinduced lung fibroblast proliferation. J Cell Mol Med 2013;17:160-167.

11. Ni YF, Wang J, Yan XL et al. Histone deacetylase inhibitor, butyrate, attenuates lipopolysaccharide-induced acute lung injury in mice. Respir Res 2010;11:33.

12. He Z, Zhu Y, Jiang H. Toll-like receptor 4 mediates lipopolysaccharideinduced collagen secretion by phosphoinositide3-kinase-Akt pathway in fibroblasts during acute lung injury. J Recept Signal Transduct Res 2009:29:119-125.
13. Meijerink J, Mandigers $C$, van de Locht $L$ et al. A novel method to compensate for different amplification efficiencies between patient DNA samples in quantitative real-time PCR. J Mol Diagn 2001;3: $55-61$.

14. He Z, Gao Y, Deng $Y$ et al. Lipopolysaccharide induces lung fibroblast proliferation through Toll-like receptor 4 signaling and the phosphoinositide3-kinase-Akt pathway. PLoS One 2012;7:e35926.

15. Shakespear MR, Hohenhaus DM, Kelly GM et al. Histone deacetylase 7 promotes Toll-like receptor 4-dependent proinflammatory gene expression in macrophages. J Biol Chem 2013;288:25362-25374.

16. Berger SL. The complex language of chromatin regulation during transcription. Nature 2007:447:407-412.

17. He Z, Deng $Y, L i ~ W$ et al. Overexpression of PTEN suppresses lipopolysaccharide-induced lung fibroblast proliferation, differentiation and collagen secretion through inhibition of the PI3-K-AktGSK3beta pathway. Cell Biosci 2014:4:2.

18. Deng Y, Yang Z, Gao $Y$ et al. Toll-like receptor 4 mediates acute lung injury induced by high mobility group box-1. PLoS One 2013;8: e64375.

19. Yang ZW, Deng YX, Su DS et al. TLR4 as receptor for HMGB1-mediated acute lung injury after liver ischemia/reperfusion injury. Lab Invest 2013;93:792-800.

20. de Ruijter AJ, van Gennip AH, Caron HN et al. Histone deacetylases (HDACs): characterization of the classical HDAC family. Biochem J 2003;370:737-749.

21. Aung HT, Schroder K, Himes SR et al. LPS regulates proinflammatory gene expression in macrophages by altering histone deacetylase expression. FASEB J 2006;20:1315-1327.

22. Joshi A, Barabutis N, Thangjam G et al. Lipopolysaccharide-induced histone deacetylase activity increases paracellular permeability in human lung microvascular endothelial cells. FASEB J 2014;28:1.

23. Serrat N, Sebastian C, Pereira-Lopes S et al. The response of secondary genes to lipopolysaccharides in macrophages depends on histone deacetylase and phosphorylation of C/EBPbeta. J Immunol 2014;192: 418-426.

24. Yasutake $T$, Wada $H$, Higaki $M$ et al. Anacardic acid, a histone acetyltransferase inhibitor, modulates LPS-induced IL-8 expression in a human alveolar epithelial cell line A549. F1000Res 2013;2:78.

25. Chen X, Xiao W, Chen W et al. The epigenetic modifier trichostatin A, a histone deacetylase inhibitor, suppresses proliferation and epithelialmesenchymal transition of lens epithelial cells. Cell Death Dis 2013;4: e884.

26. Xiao W, Chen X, Liu X et al. Trichostatin A, a histone deacetylase inhibitor, suppresses proliferation and epithelial-mesenchymal transition in retinal pigment epithelium cells. J Cell Mol Med 2014;18: 646-655.

27. Sato TA, Mitchell MD. Molecular inhibition of histone deacetylation results in major enhancement of the production of IL-1beta in response to LPS. Am J Physiol Endocrinol Metab 2006;290:E490-E493.

28. Shan B, Hagood JS, Zhuo Y et al. Thy-1 attenuates TNF-alpha-activated gene expression in mouse embryonic fibroblasts via Src family kinase. PLoS One 2010;5:e11662.

29. Thangjam GS, Joshi AD, Barabutis $\mathrm{N}$ et al. HSP90 inhibition attenuates LPS-mediated NF-(kappa) B-dependent gene activation by preventing the de-acetylation and maintaining the DNA binding of acetyl-histone $\mathrm{H} 3$ (K9) in human lung microvascular endothelial cells (HLMVEC). FASEB J 2013;27:724.15.

30. Angrisano T, Pero R, Peluso $S$ et al. LPS-Induced IL-8 activation in human intestinal epithelial cells is accompanied by specific histone $\mathrm{H} 3$ acetylation and methylation changes. BMC Microbiol 2010;10:172.

31. Choo QY, Ho PC, Tanaka Y et al. Histone deacetylase inhibitors MS-275 and SAHA induced growth arrest and suppressed lipopolysaccharidestimulated NF-kappaB p65 nuclear accumulation in human rheumatoid arthritis synovial fibroblastic E11 cells. Rheumatology (Oxford) 2010:49:1447-1460. 